\title{
Inclusão escolar pela via da colaboração entre educação especial e educação regular ${ }^{1}$
}

\section{School inclusion through collaboration between special education and general education}

\author{
Eniceia Gonçalves Mendes ${ }^{2}$ \\ Maria Amélia Almeida ${ }^{3}$ \\ Cristina Yoshie Toyoda ${ }^{4}$
}

\begin{abstract}
RESUMO
A preocupação sobre as práticas inclusivas nas escolas públicas no Brasil começou após a Declaração de Salamanca, com desafios e dúvidas. Ainda hoje, passados cerca de 15 anos, os professores do ensino regular se queixam dizendo que não têm conhecimento suficiente ou preparo formal para lidar com crianças com necessidades educacionais especiais, especialmente quando estas apresentam disfunções graves, como paralisia cerebral, deficiência intelectual e comportamentos desafiadores. A colaboração entre profissionais da Educação Especial e Regular pode ser uma alternativa para enfrentar tais desafios. O objetivo deste relato foi o de apresentar um breve histórico de um programa de pesquisa, ensino e extensão que busca aproximar a Universidade Federal de São Carlos dos professores do ensino comum que têm alunos com necessidades especiais em suas salas de aula. Iniciado em 2004, este programa está na atualidade em seu sétimo ano de execução e envolve professores da universidade, estudantes de graduação
\end{abstract}

${ }^{1}$ Apoio: Programa de Extensão Universitária do Ministério da Educação/Secretaria de Educação Superior (ProExt/MEC/SESu), Conselho Nacional de Desenvolvimento Científico e Tecnológico (CNPq) e Pró-Reitoria de Extensão da Universidade Federal de São Carlos (UFSCar).

2 Professora Associada da UFSCar, Brasil E-mail: egmendes@ufscar.br.

${ }^{3}$ Professora Associada da UFSCar, Brasil. E-mail: ameliama@terra.com.br.

${ }^{4}$ Professora Doutora da Universidade Estadual Paulista (UNESP) Marília, Brasil. E-mail: cristoyoda@gmail.com. 
e pós-graduação e professores do ensino comum. Os resultados parecem apontar essa via de colaboração entre Educação Especial e Regular como um caminho promissor para a construção de escolas mais inclusivas.

Palavras-chave: inclusão escolar; ensino colaborativo; consultoria colaborativa; formação de profissionais.

\begin{abstract}
The concern about inclusive practices in public schools in Brazil began after the Salamanca Statement, with challenges and doubts. Even today, after about 15 years, the regular teachers complain saying they did not have enough knowledge or formal preparation for dealing with children with special educational needs, especially when they have serious disorders such as cerebral palsy, intellectual disabilities and behavior disorders. The collaboration between professionals of Special and Regular Education can be an alternative to face these challenges. The objective of this report was to present a brief history of a program on research, teaching and extension that aims to bring together the Federal University of São Carlos and regular school teachers who have students with special needs in their classrooms. The program started in 2004 and currently is in its seventh year of implementation, involving university professors, undergraduate and postgraduate students and regular teachers. The results seem to point out that collaboration between Regular and Special Education can be a promising avenue for making more inclusive schools.

Keywords: school inclusion; collaborative teaching; collaborative consultation; professional preparation.
\end{abstract}

\title{
Introdução
}

O movimento pela educação inclusiva no Brasil teve um grande impacto na discussão de políticas educacionais para crianças e adolescentes com necessidades especiais uma vez que a grande maioria desta população havia sido historicamente excluída do sistema educacional público brasileiro.

Durante a Conferência Mundial de Educação para Todos, em Jomtien, Tailândia, em 1990, o Brasil estabeleceu metas básicas para melhorar o sistema educacional brasileiro. Entre esses objetivos, parecia necessário melhorar a educação de crianças e adolescentes com necessidades especiais. Como resultado da Conferência Mundial sobre Necessidades Educativas Especiais: Acesso e 
Qualidade, organizada pelo Governo espanhol e pela UNESCO em junho de 1994, a Declaração de Salamanca foi aprovada. Teorias e práticas baseadas no princípio da inclusão escolar começaram a ser discutidas com maior ênfase no Brasil.

Assim que os sistemas de ensino público demonstraram o desejo de mudanças políticas, começou a aumentar a matrícula de crianças com necessidades educacionais especiais em classes comuns e o horizonte para a pesquisa sobre a inclusão escolar se abriu. Em decorrência dessa mudança política, começamos a intensificar a linha de pesquisa sobre inclusão escolar no âmbito da Universidade Federal de São Carlos, e teve início o estudo de caso do nosso município onde na época se observava uma vontade política de implementar a política de inclusão escolar, expressa na oferta de um curso abrangente visando a sensibilizar todos os educadores sobre os princípios da educação inclusiva.

A despeito de todo o otimismo sobre a política de inclusão escolar, os dados oficiais do Ministério de Educação no Brasil mostravam na época uma estatística ainda tímida relacionada à quantidade total de alunos com necessidades especiais matriculados no ensino regular. No ano de 1998, por exemplo, havia 400 mil alunos matriculados (MEC/SEESP, 2001). As escolas especiais eram responsáveis por $63 \%$ das matrículas dos alunos com necessidades especiais matriculados no sistema educacional. No ano de 1999, a proporção de matrículas em escolas especiais diminuiu para cerca de $60 \%$ e a de matrículas em classes especiais também diminuiu de 24,7\%, em 1998, para 22,5\%, em 1999.

Fizemos algumas experiências iniciais e constatamos que a preparação de professores por meio de cursos de curta duração não produzia os resultados esperados, uma vez que os professores continuavam chamando nossa atenção com a sensação de isolamento, impotência e incompetência para lidar com crianças com necessidades educacionais especiais inseridas em suas salas de aula, a despeito dos muitos cursos que haviam realizado. As principais solicitações dos professores estavam relacionadas à falta de profissionais especializados que fossem capazes de oferecer suporte de forma mais sistemática no dia a dia do processo educativo com essas crianças. No entanto, as possibilidades do município para atender a estes pedidos eram limitadas devido à falta de profissionais da educação especial no sistema de educação e saúde pública, associado à dificuldade em contratar novos funcionários.

Diante desta situação, como pesquisadores, começamos a nos preocupar também com a questão de como a Universidade poderia assumir a responsabilidade de qualificar os recursos humanos envolvidos, principalmente nos cursos de formação inicial com o objetivo de evitar necessidade de formação continuada permanente. Uma das soluções postas em prática no ano de 2004 foi o Projeto "S.O.S. Inclusão" (MENDES; TOYODA, 2005). 


\section{O princípio do Projeto S.O.S. Inclusão}

O projeto começou com a questão sobre como oferecer aos professores da escola comum suporte para qualificar o trabalho pedagógico desenvolvido por eles com seus alunos com necessidades educacionais especiais. As ações de formação para educadores com base no formato de cursos de curta duração, apesar de serem realizadas com a parceria de universidades e associadas à vontade e interesse político do poder público, não foram suficientes para produzir resultados mais significativos.

A literatura sobre a educação inclusiva aponta várias estratégias para as escolas minimizarem as barreiras de aprendizagem e caminhar em direção à qualidade de ensino para todos os alunos. Entre essas estratégias, destacam-se a recomendação de oferecer informações e quebrar mitos e preconceitos; garantir formação permanente para todos os profissionais envolvidos no processo; valorizar o professor, que é o responsável por importantes tarefas da escola; e estabelecer sistemas de colaboração e/ou de cooperação, criando e/ou fortalecimento uma rede de apoio. Enfim, os estudos sobre a inclusão escolar têm forçado a adesão ao princípio de que os professores não devem trabalhar sozinhos, mas em equipes compostas por um grupo de pessoas cujas respostas e funções sejam derivadas de filosofia e objetivos mútuos (MADDUX, 1988 apud GARGIULO, 2003).

Autores como Wood (1998) e Federico, Herrold e Venn (1999) defendem que os modelos de colaboração entre professores, pais e demais profissionais das escolas, que têm sido implementados para atender à diversidade, já são reconhecidos como estratégias poderosas e bem sucedidas. O poder das equipes colaborativas está na capacidade de encontrar educadores com talento e habilidades únicos para promover sentimento positivo interdependente para desenvolver as habilidades criativas de solução de problemas, bem como para promover apoio mútuo e responsabilidade compartilhada. Dentre as formas de trabalho colaborativo na escola encontramos dois modelos: "o coensino" ou "ensino colaborativo" e a "consultoria colaborativa".

Bauwens, Hourcade e Friend (1989) foram os primeiros a descrever uma associação entre professores do ensino regular e especial, e nomearam essa relação de ensino colaborativo. Cook e Friend (1995) abreviaram o termo "ensino colaborativo" para "coensino" e, progressivamente, clarearam as características inerentes a uma verdadeira relação de colaboração, definindo coensino como: "dois ou mais profissionais dando instruções substantivas para um diverso ou misto grupo de alunos num único espaço físico" (COOK; FRIEND, 1995, p. 2). 
O ensino colaborativo ou coensino é um modelo de prestação de serviço de educação especial no qual um educador comum e um educador especial dividem a responsabilidade de planejar, instruir e avaliar a instrução de um grupo heterogêneo de estudantes. Ele emergiu como uma alternativa aos modelos de sala de recursos, classes especiais ou escolas especiais, como um modo de apoiar a escolarização de estudantes com necessidades educacionais especiais em classes comuns. Assim, a invés dos alunos com necessidades educacionais especiais irem para classes especiais ou de recursos, é o professor especializado que vai até a classe comum na qual o aluno está inserido colaborar com o professor do ensino regular.

O modelo de consultoria colaborativa existe desde 1990 na literatura educacional (WEST; IDOL, 1989; PUGACH; JOHNSON, 1995; KAMPWIRTH, 2003; IDOL; PAOLUCCI-WHITCOMB; NEVIN, 2000). Consultoria é um processo que tem seis características: 1) é uma ajuda ou processo de resolução de problemas; 2) ocorre entre alguém que recebe ajuda e alguém que dá a ajuda e que tem a responsabilidade pelo bem estar de uma terceira pessoa; 3 ) é uma relação voluntária; 4) tanto quem dá ajuda quanto quem a recebe compartilha a solução do problema; 5) a meta é ajudar a resolver um problema de trabalho atual de quem busca a ajuda; e 6) quem ajuda se beneficia da relação, de modo que os futuros problemas poderão ser controlados com mais sensibilidade e habilidade.

A consultoria para o professor é um processo de resolução de problema que toma parte num período de tempo e segue determinados estágios. Durante este processo, o consultor assiste o professor de sala de aula para maximizar o desenvolvimento educacional dos estudantes. A consultoria enfoca um problema de trabalho atual do consultado. O processo é diferenciado tanto das supervisões quanto do aconselhamento, porque o intercâmbio é colaborativo, havendo uma ênfase no papel igualitário do consultado na contribuição para a resolução do problema, e o consultado está livre todo o tempo para aceitar ou rejeitar as soluções recomendadas durante a consultoria.

Assim, considerando a dificuldade de melhoria das oportunidades educacionais para alunos com necessidades educacionais especiais na sala de aula regular e a necessidade de avançar o conhecimento sobre as alternativas mais eficazes para a preparação de profissionais envolvidos na construção de sistemas inclusivos, o projeto inicial teve como objetivo geral implementar e avaliar um programa de consultoria colaborativa para as escolas regulares com a intenção de colaborar no processo de inclusão escolar de crianças com necessidades educacionais especiais. Assim, o projeto inicial teve como objetivo investigar as possibilidades de trabalho colaborativo em dois momentos: formação dos estudantes na universidade e formação continuada de professores de crianças com necessidades educacionais especiais. 
Os objetivos específicos do projeto foram:

- Relacionados a programas de extensão da Universidade: 1) Favorecer o desenvolvimento de escolas inclusivas e creches no município de forma a garantir a médio e longo prazo a ampliação do acesso a melhores oportunidades educacionais para alunos com necessidades educacionais especiais; 2) Promover melhoria na qualidade do ensino oferecido pela rede pública municipal de alunos com necessidades educacionais especiais e respectivas famílias com serviços de apoio.

- Relacionadas ao ensino: 1) Oferecer aos estudantes de graduação (Educação Física, Fisioterapia, Educação, Psicologia, Terapia Ocupacional) a experiência prática em equipes interdisciplinares; 2) Ampliar oportunidades a alunos desses cursos de graduação a experimentar habilidades de reflexão sobre a prática e relacionar teoria e prática em situações reais de trabalho; 3 ) Oferecer aos alunos desses cursos oportunidade de formação teórico-prática em locais emergentes de trabalho na sociedade, que seria a equipe multidisciplinar, com a função de consultoria e de colaboração para apoio à inclusão escolar.

A intervenção foi baseada no modelo de "consultoria colaborativa" de profissionais para educadores do ensino regular que tinham alunos com necessidades educacionais especiais incluídos em suas salas de aula. O trabalho colaborativo era realizado em diferentes instâncias: nas reuniões de supervisão na Universidade, envolvendo pesquisadores colaboradores, e na escola, envolvendo visitas semanais de pelo menos um membro de cada equipe na sala de aula onde professores tivessem alunos com necessidades educacionais especiais. Em tais situações, os problemas e dificuldades dos professores relacionados aos alunos com necessidades especiais eram analisados coletivamente nas reuniões de grupo na universidade até as estratégias possíveis serem coletivamente identificadas e levadas para serem negociadas com os professores para uma possível implementação na escola regular.

No ambiente escolar os estudantes iam para sala de aula onde faziam observação participante. A forma de participação era definida com o professor de sala de aula, conforme estabelecido em acordo anterior. Retirar a criança alvo de sala de aula, bem como atuação dirigida exclusivamente para ele/ela deveria ser evitado, atendendo aos pressupostos da atuação colaborativa e da inclusão escolar. Cada universitário ficava responsável por colaborar com uma professora e seu aluno durante todo o semestre letivo.

No primeiro ano de existência, o projeto consistiu em uma atividade de pesquisa e extensão universitária e seu desenvolvimento foi apoiado financeiramente. Os recursos disponíveis permitiram a realização de 500 visitas às escolas, 
com mais de 2.000 horas de intervenção direta em sala de aula regular junto a professores de crianças com necessidades educacionais especiais. O projeto envolveu 15 horas de reuniões de supervisão semanais na universidade, que foram videogravadas: 30 diários de campo que incluíram os relatos das visitas individuais dos universitários nas escolas.

Na primeira etapa do programa, o projeto envolveu dois professores universitários, 30 estudantes de graduação dos cursos de Educação, Psicologia, Educação Física, Terapia Ocupacional e Fisioterapia, 30 professores do ensino regular de 16 unidades escolares (creches, escolas de educação infantil e escolas de ensino fundamental) e 60 alunos com necessidades educacionais especiais incluídos nessas unidades educacionais.

A análise do conteúdo dos diários de campo permitiu a identificação de 11 categorias nos registro dos estudantes universitários e sobre questões relacionadas a "o quê" ou "quem" era o alvo do episódio relatado, tais como: o professor, a criança-alvo, os companheiros de sala de aula, o diretor, a Secretaria de Educação e a ação do aluno universitário. Por meio dos registros, foi constatado que o estágio colaborativo, como é definido na literatura, parecia difícil de ser implementado desde o princípio, sendo necessário negociar e iniciar várias vezes todo o processo do papel do colaborador.

A análise dos relatórios dos 43 estudos de caso sobre as crianças-alvo desta primeira etapa do projeto indicou que as dificuldades acadêmicas foram a razão principal para encaminhamento e esteve presente em 18 casos (44\%) e seis crianças em idade escolar foram apontadas como analfabetas (SANTOS, 2006). Além dos problemas acadêmicos, dificuldades de comunicação também foram frequentes (17 casos, ou 39\%), seguidas por problemas de saúde (seis casos ou 15\%). Também foi relatado como uma causa para as condições de encaminhamento a deficiência, tais como: deficiência visual (seis crianças), deficiência física (15 crianças, sendo seis com paralisia cerebral), deficiência intelectual (11 crianças) e duas crianças com deficiência auditiva. Entre as razões das referências acima, também foram indicadas: dificuldades de comportamento em 14 casos, dificuldades motoras em dois casos e dificuldades de socialização em dois casos.

Em geral, os resultados positivos encontrados nos relatórios dos casos foram relacionados em $41 \%$ dos casos e os benefícios moderados em $46 \%$ dos casos. Apenas em 12\% dos casos os benefícios não foram identificados. Em termos de impacto da intervenção sobre as crianças-alvo, os efeitos mais positivos foram observados nos seguintes domínios: socialização (24 crianças ou $58 \%$ ), habilidades acadêmicas ( 23 ou $56 \%$ ) e linguagem (22 ou 54\%). Ao final do ano letivo, os colaboradores universitários indicaram a necessidade de manter este serviço de apoio para os professores. 
Em 2010 este projeto completou sete anos tendo já se tornado em atividade regular na universidade, sendo suas atividades sustentadas enquanto disciplinas e como um projeto de extensão desenvolvido em parceria com a secretaria de educação do município. Uma breve descrição dos principais resultados observados até o presente momento será fornecido a seguir.

\section{A transformação do Projeto S.O.S. em atividades regulares}

No segundo ano, em 2005, o projeto teve restrições financeiras e para manter as atividades e torná-las regulares foram criadas duas disciplinas, sendo uma oferecida no primeiro semestre e outra oferecida no segundo semestre para alunos de Pós-Graduação em Educação Especial. Os participantes eram estudantes de graduação e de pós-graduação das disciplinas "Inclusão escolar e ensino colaborativo" e "Inclusão escolar e consultoria colaborativa" durante os anos letivos de 2005 a 2010.

Durante essas aulas, os estudantes da universidade da graduação e da pós-graduação eram expostos à literatura internacional sobre este modelo, a fim de se prepararem para discutir com os professores e colegas as melhores práticas sobre este modelo; Simultaneamente eles deveriam praticar estes princípios com professores do ensino regular que tivessem crianças com necessidades especiais em suas salas de aula. Os estudantes entrevistavam os professores de sala de aula no início, a fim de verificar as principais dificuldades que estes enfrentam para lidar com seus alunos. Depois passavam a participar das atividades da classe comum um dia por semana, observando o professor e sua turma, oferecendo assistência aos professores em termos de dicas úteis e parceria na sala de aula para o ensino e planejamento do conteúdo, além de oferecer suportes adicionais, se necessário. Todas as atividades eram registradas em diário de campo e ao final eles elaboravam um relatório sobre o aluno acompanhando ao longo do semestre.

Neste segundo ano (2005), nossos universitários puderam assistir 20 professores e suas respectivas 20 crianças com necessidades educacionais especiais. A associação do projeto às disciplinas de pós-graduação permitiu ampliar o embasamento teórico sobre a prática profissional de apoio à inclusão escolar de alunos com necessidades educacionais especiais.

No terceiro ano de funcionamento, em 2006, além das disciplinas de pós-graduação, foram criadas mais duas disciplinas para a graduação em Psicologia nos mesmos moldes: com leituras, discussão de texto, atividades práticas (visitas escolares, diário de campo, estudo de caso e relatórios de supervisão coletiva). 
Neste ano, sete alunos de pós-graduação e nove alunos da graduação acompanharam 16 professores e seus respectivos alunos com necessidades educacionais especiais, e foi incluída uma reunião final de avaliação das atividades de consultoria colaborativa com a participação de todas as pessoas envolvidas no projeto.

No quarto ano de funcionamento (2007), o projeto foi desenvolvido como nos anos anteriores, com nove alunos da graduação em Psicologia e dezessete da Pós-Graduação em Educação Especial. Participaram neste ano 26 professores e seus respectivos alunos da rede, muitos deles apresentando comportamentos desafiadores.

No quinto ano do projeto (2008), participaram sete alunos da graduação em Psicologia e sete da Pós-Graduação, e foram acompanhadas 14 professoras e suas respectivas crianças com necessidades educacionais especiais.

No sexto ano do projeto, em 2009, participaram cinco alunos de graduação em Psicologia e sete alunos de Pós-Graduação em Educação Especial.

Em 2010, participaram três alunos da graduação e 12 alunas da pós-graduação, tendo sido acompanhadas 17 professoras, bem como suas respectivas crianças.

O que tem sido observado ao longo dessa história foi a construção de uma cultura de colaboração, de modo que a cada ano tem se tornado mais e mais fácil atingir um estágio de colaboração com os professores desde o início do trabalho. Hoje os professores da rede conhecem a proposta de trabalho e a maioria compreende o que significa e busca trabalhar junto. A evidência disso tem sido o aumento na demanda de professores que requisitam participar do Projeto. Em 2010, um total de 53 professores da rede se inscreveu para participar do projeto e receber colaboração dos estudantes da universidade, número este bem acima da demanda que temos conseguido atender, pois, além do número de estudantes ser variável de ano para ano, é difícil supervisionar um grande número de universitários, dado às demandas de, ao mesmo tempo, formar os estudantes e prestar os serviços de modo a resolver os problemas trazidos pelos professores sobre os mais variados assuntos.

Ressalta-se ainda que a disciplina é aberta ao público externo e que tem aumentado muito a procura de alunos ouvintes para essas disciplinas de ensino e consultoria colaborativa.

\section{Conclusões}

Os resultados de nossa experiência ao longo destes anos indicam que a aprendizagem colaborativa oferece grandes vantagens que não estão disponí- 
veis em ambientes de aprendizagem mais tradicionais, uma vez que o grupo permite um grau mais significativo de aprendizagem e reflexão do que qualquer indivíduo poderia fazer de forma isolada. Durante todo o diálogo, a maneira que cada pessoa tem de pensar se torna público e ela explica e defende seu ponto de vista. Quando pessoas estão envolvidas em interações grupais, frequentemente podem superar situações que não são capazes de perceber quando estão sozinhas, trabalhando de forma independente. Estes resultados foram evidenciados nas aulas, nos relatórios de alunos e apontados pelos professores regulares envolvidos no projeto.

Os relatórios de estudos de casos apresentados pelos alunos demonstram resultados positivos para as crianças com necessidades educacionais especiais e seus professores. No final da intervenção, o ambiente nas salas de aula, de modo geral, se torna mais colaborativo, e os professores revelam sentirem-se mais confiantes sobre como lidar com as crianças especiais em suas salas de aula. Tem sido recorrente a constatação pelos professores de que as melhorias no ensino introduzidas para responder às necessidades educacionais particulares de alguns alunos acabam beneficiando também aos demais colegas da sala.

Os estudantes da universidade desenvolvem habilidades interpessoais e de comunicação necessárias para a colaboração e se sentem mais confiantes sobre o seu papel como consultor, vendo aí uma nova perspectiva para seu trabalho no futuro. Eles aprendem a analisar e discriminar atitudes que favorecem ou prejudicam a parceria colaborativa e se tornam cada vez mais capazes de conciliar a teoria com a realidade experimentada pelos professores nas escolas

Os dados dos diários de campo e os materiais dos alunos com necessidades especiais demonstram ganhos em muitas dimensões, não só escolares. Além disso, é importante registrar as mudanças obtidas em vários casos nas atitudes dos professores e das crianças não deficientes em relação aos alunos com necessidades educacionais especiais.

No conjunto, os resultados obtidos mostram que, além do trabalho de colaboração entre a universidade e as escolas ser eficaz para resolver os problemas (administrativos, pedagógicos, comportamentais), também promove o desenvolvimento pessoal e profissional de todos os envolvidos (pesquisadores, estudantes de graduação e pós-graduação, professores, diretores, alunos com necessidades especiais), além de promover também o desenvolvimento de escolas inclusivas no município.

Além disso, é importante ressaltar a oportunidade real de experiências de trabalho em escolas públicas, uma realidade que ainda é desconhecida para muitos estudantes brasileiros das universidades públicas.

A elaboração dos diários de campo tem sido um bom método para treinar os universitários em habilidades de reflexão sobre a prática, por um lado, e, por 
outro, tem permitido compreender e avaliar intervenções inovadoras no sistema de ensino. Essas anotações de diário de campo também permitem a indicação de fatores que estão envolvidos no trabalho e vão contribuir e muito para o estudo de novas práticas. Em geral, por meio da análise dos diários de campo, foi possível notar que a consultoria colaborativa pode gerar efeitos importantes, principalmente em relação às mudanças nas práticas de professores do ensino regular que tenham alunos com necessidades educacionais especiais em suas salas de aula.

A despeito da avaliação positiva, também foi possível constatar que ainda existe uma falta de preparo por parte dos professores para lidar com este tipo de trabalho colaborativo, uma vez que, a princípio, prevalece uma tendência de atribuir tarefas e esperar que o colaborador assuma a responsabilidade da criança com necessidades especiais matriculada em suas salas de aula, enquanto eles preferem dedicar o seu tempo para os outros alunos. Quando isso acontece, é necessário negociar desde o início o papel do colaborador e uma possível solução poderia se desenvolver na formação inicial das competências desejáveis para um trabalho colaborativo nas escolas.

No presente talvez uma das mudanças mais desafiadoras para os professores seria abandonar este papel tradicionalmente individual, de controle absoluto da sala de aula, para começar a agir de forma a compartilhar objetivos, tomadas de decisões, instruções, responsabilidades, avaliação da aprendizagem, resolução de problemas e enfim tudo o que envolve a administração da sala de aula. Nesse sentido, os professores e profissionais precisam começar a pensar como "nossa" classe para superar medos e tensões inevitáveis associados às mudanças (BAUWENS; HOURCADE; FRIEND, 1995).

\section{REFERÊNCIAS}

ARGÜELlES, M. E.; HUGHES, M. T.; SCHUMM, J. S. Co-Teaching: A Different Approach to Inclusion. Principal (Reston, Va.), v. 79, n. 4, p. 50-51, 2000.

BAUWENS, J.; HOURCADE, J. J.; FRIEND, M. Cooperative teaching: a model for general and special Education. Remedial and Special Education, v. 10, n. 2, p. 17-22, 1989.

BRASIL, MINISTÉRIO DA EDUCAÇÃO/Secretaria de Educação Especial (SEESP). Censo Escolar. Disponível em: <http://portal.inep.gov.br/basica-censo-escolar-sinopse-sinopse>. Acesso em: 13/10/2010. 
COOK, L.; FRIEND, M. Co-teaching: Guidelines for creating effective practices. Focus on Exceptional Children, v. 28, n. 3), p. 1-16, 1995.

FEDERICO, M. A.; HERROLD, W. G. Jr.; VENN, J. Helpful tips for successful inclusion. Teaching Exceptional Children, v. 32, n. 1, p. 76-82, 1999.

GARGIULO, R. M. Education on contemporary society: an introduction to exceptionality. Thomson Learning: United Station, 2003.

GATELY, S. E.; GATELY, F. J. Understanding Coteaching Components. Teaching Exceptional Children, v. 33, n. 4, p. 40-47, mar.-apr. 2001.

IDOL, L. Key questions related to building collaborative and inclusive schools. Journal of Learning Disabilities, n. 30, 384-394, 1997.

; PAOLUCCI-WHITCOMB, P.; NEVIN, A. Collaborative consultation( $3^{\text {rd }}$ ed.). Austin, TX: PRO-ED, 2000.

JOHNSON, L. J.; PUGACH, M. C. Role of Collaborative in Teacher's Conceptions of Appropriate Practice for Students at Risk. Journal of Educational and Psychological consultation, v. 7, n. 1, p. 9-24, 1996.

KAMPWIRTH, Thomas J. Overview of School-Based Consultation In: Collaborative consultation in the schools: effective practices for students with learning and behavior problems. . New Jersey: Merril Prentice Hall, 2003. p. 01-39.

MENDES, E. G.; TOYODA, C. Y. Projeto S.O.S. Inclusão - Consultoria colaborativa para favorecer a inclusão escolar num sistema educacional municipal. Relatório Final. (MEC/SESu Processo 269/03/ PRO-EX/UFSCAR). Universidade Federal de São Carlos. Mimeo, 2005.

PUGACH, M.; L. JOHNSON. Collaborative practitioners, collaborative schools. Denver, Colo: Love Publishing, 1995.

SANTOS, F. M. S.O.S. Inclusão: análise da documentação do programa de consultoria colaborativa baseada nos estudos de casos. Iniciação Científica (Graduação em Pedagogia) - Conselho Nacional de Desenvolvimento Científico e Tecnológico, Universidade Federal de São Carlos, 2006.

WALTHER-THOMAS, C. Co-teaching experiences: The benefits and problems that teachers and principals report over time. Journal of Learning Disabilities, n. 30, p. 395-407, 1997.

; KORINEK, L.; McLAUGHLIN, V. L. Collaboration to support student's success. Focus on Exceptional Children, v. 32, n. 3, p. 1-18, 1999.

; BRYANT, M.; LAND, S. Planning for effective co-teaching: The key to successful inclusion. Remedial and Special Education, v. 17, n. 4, p. 255-264, 1996. 
WEST, F.; IDOL, L. Collaboration in the Schools: Communicating, Interacting and Problem-Solving. Austin, Texas: Pro-Ed, 1989.

WOOD, M. Whose job is it anyway? Educational roles in inclusion. Exceptional Children, v. 64, n. 2, p. 181-195, 1998.

Texto recebido em 03 de fevereiro de 2011.

Texto aprovado em 02 de maio de 2011. 